\title{
Effect of Online Travel Bookings and Social Media on Tourism Destination Marketing in Nigeria
}

\author{
Elizabeth Abiola-Oke ${ }^{1 *}$, Christopher O. Aina ${ }^{2}$ \\ ${ }^{1}$ Department of Transport and Tourism Studies, Redeemer's University, Ede Osun State \\ ${ }^{2}$ Department of Tourism and Events Management, College of Social and Management Sciences, \\ Afe Babalola University
}

*Corresponding author email: jacobe@ run.edu.ng

Received: 18 April 2019 / Revised: 30 June 2019 / Accepted: 8 July 2019 / Published: 18 July 2019

\begin{abstract}
AB STRACT
The impact of information and Communication Technologies (ICTs) is also felt in the field of tourism as it plays an essential role in the development and marketing of tourism. The study focused on the growth of Online Travel Booking in the tourism industry in terms of the internet, mobile and social media in a country like Nigeria where there are tons of tourist destinations across the country. Both primary and secondary data were used for this study. A questionnaire was designed to collect primary data. The survey was distributed to a sample of 222 students of Redeemer's University through the random selection of both genders. The Chi-square method was employed in analysing the data. Out of 222 questionnaires administered, only 200 were retrieved. Flights and Hotel reservations can be made online through e-mail, telephone calls and other internet services thereby helping to reduce if not remove the time-wasting processes of the old system entirely. It is, therefore, evident that its adoption is necessary for proper inclusion in these benefits and sustainable development of tourism.
\end{abstract}

Keywords: Tourism, Social Media, Online Travel Booking, Tourism Development, e-commerce, Information and Communication Technology

\section{Introduction}

The Tourism industry is information-intensive, and according to Sheldon (1993), information is the lifeblood of the tourism industry, and the industry cannot function effectively without it. Past studies have revealed the influence of online travel booking on tourism. This is due to the digital revolution that has put an end to manual operation of businesses in almost all industries, tourism not left out (Wahab, 2017). Due to this, there came the advent of online travel booking through sites such as Expedia which gave a one_stop shop for tourists to make reservations for all the services they will require for their trip (Carey, 2012). According to Wahab (2017), Information Technology plays a central role in the growth and improvement of the travel and tourism industry. Due to the information technology, travellers are able to make informed decision on destination to visit. According to Mamaghani (2009), almost three-fourths of online travel buyers used search engines before making any travel purchase. In addition to the Internet, technology gadgets such as Geographic Positioning System (GPS), mobile phones, smartphones and hand-held devices have improved consumers' tourism and travel experiences. Information accessibility regarding travel, destination, bookings, payments, hotels, attractions, and the quality of maps are areas for improvement (Mamaghani, 2009).

While e-commerce across the rest of the world is growing at 16.8 per cent, Africa's e-Commerce space is growing at a rate of $25.8 \%$, making it the fastest growing in the world (Tonye, 2015). This rapid growth has been fuelling a massive consumer behavioural change in favour of online travel booking. Oguntude and Oyeyipo, (2012) observed that the level of Internet usage in Nigeria remains relatively low compared to developed countries and e-commerce is still in an elementary stage, notwithstanding there is a growing

Copyright (C) 2019. The Author(s). Published by AIJR Publisher.

This is an open access article under Creative Commons Attribution-NonCommercial 4.0 International (CC BY-NC 4.0) license, which permits any non-commercial use, distribution, adaptation, and reproduction in any medium, as long as the original work is properly cited. 
awareness of the benefits and opportunities offered by e-commerce amongst Nigerians (Bamodu, 2005). Tourism in Nigeria is still in its infancy stage considering the massive accumulation of resources which are yet untapped and the institutional structure which is, however, to be regulated to compete favourably with other fast-growing tourism destinations. Successive governments have tried their best to put the tourism industry in the national economic map, but the sector could not meet up with the exclusive listing. This research work aims to examine the growth of online travel booking in tourism sector focusing on the aspect of the internet, mobile and social media in a country like Nigeria where there are lots of tourist destinations across the country.

\subsection{Research Hypotheses}

Two hypotheses were tested to identify the effect of Social media on tourism development in Nigeria; these are:

i. There is no significant relationship between the usage of the mobile device and travel bookings in Nigeria.

ii. There is no significant relationship between social media and tourist/traveller's behaviour

\section{Literature Review}

\subsection{Information and Communication Technology, and Tourism}

The role of Information and Communication Technology in the Tourism and Travel industry cannot be over-emphasised, considering how information-intensive the industry is. According to Iriobe \& AbiolaOke, (2019), Information technology and social media has made it easy for people to access information on tourism destinations, and that at a faster rate. Tourism, unlike a physical product, is intangible and cannot be pre-tested or tried before purchase; therefore, access to accurate, reliable, timely and relevant information is essential to help tourists and travellers make appropriate choices (Go and Pine, 1995). Wahab (2017) stated that one of the major problems confronting the tourism industry is the provision of correct, accurate and localised information, and along side maitaining a good relationship with customers. According to her, this can only be solved by Information technology. In line with this, it is seen that tourism is revolutionalising itself alongside the information technology.

On a global scale, Euromonitor (2016) recorded continuous growth in Online Travel, but as the market matures, the increase is less dramatic annually compared to previous years. The report further stated that Short -term rentals increase in online value for 2015 at $17 \%$, but airline remains the leading online travel category, and the mobile channels account for $18 \%$ of all online sales with online travel agents benefiting more in 2015 with a value of USD67 billion worth of mobile purchases. Online travel booking is fast penetrating and bringing new business opportunities to the travel and tourism industry globally.

Tourism-related institutions and Internet companies are coming together to tap into the potential market created by e-commerce. Beyond the benefits of e-commerce to tourism-related institutions, e-commerce is fast shaping tourists' behaviour and preferences. According to Sofronov (2018), the internet has revolutionised the tourism industry as both a source of information to customers and a channel for sales of the tourism products. This has enhanced the promotion of destinations and the services to tourists. Aside from the internet, other technology gadgets such as GPS's, mobile phones, smartphones and handheld devices have improved tourism and travel experiences of tourists. Accessibility to Information on travel, destinations, bookings, payments, hotels, attractions, and the quality of maps should be focused on for improvement.

One of the most popular online activities is the increasing numbers of travellers' use the Internet for travel planning and, search for travel-related information. According to Forrester (2006a)'s estimate, current online travel spending is $\$ 73$ billion, representing $35 \%$ of total online spending, and more than $80 \%$ of web shoppers make use of other consumers' reviews in their plans for travel (Forrester, 2006b). Similarly, Compete, Inc (2006) found that almost $50 \%$ of travel purchasers visited message board, forum, or online 
Abiola-Oke et al., Adv. J Social Sci.; Vol. 6 Issue 1, pp: 10-16, 2020

community for their online travel purchase, and one in three of these buyers indicated that consumer reviews helped with their purchase decision. Hence the importance of information technology and enhancement of social media by the availability of internet.

\subsection{Online Travel Booking and Social Media}

Online travel booking is fast penetrating, and it brings new business opportunities to the travel and tourism industry globally. Tourism-related institutions and Internet companies are coming together to tap into the potential market created by e-commerce. Beyond the benefits of e-commerce to tourism-related institutions, e-commerce is fast shaping tourist's behaviour and preferences. Information technology has introduced online travel booking through the introduction of the Internet and the World Wide Web, which has impacted both consumer and industry behaviours in terms of travel and tourism (Mamaghani, 2009). According to Xinran, Dae- Young \& Morrison (2006), consumers have more options regarding vacation and budget planning. Ninety-five per cent of web users have searched the Internet to gather travel related information. Ninety-three per cent visited destination web sites, and nearly one half used e-mail to collect travel-related information. According to the World Trade Organisation (W'TO), the Internet is transforming the spread of tourism information and sales. An increasing number of Internet users are purchasing travel online, and tourism will gain a large share of the online commerce market. The Internet has a significant impact as a source of information for tourism; and indeed, technologies can contribute handsomely to tourism development (Chulwon, 2004). For tourism businesses, the Internet offers the opportunity to make information and booking facilities available to a large number of tourists at a low cost. It also provides a tool for communication between tourism suppliers, intermediaries, as well as end-consumers. Organisation for Economic Co-operation and Development ((OECD), 2000) revealed that the advent of Internet-based electronic commerce offers significant opportunities for firms to expand their customer base, enter new product markets and rationalise their business.

Although social media is essential all over the World, it still has no academically agreed definition in the literature, and it can be interpreted in diverse ways such as the definition by Fotis et al., (2012) who sees it as social software, social web sites, consumer-generated media, user-generated media, user-generated content websites, or even Web 2.0. Web 2.0 made available some technologies offering new and more efficient ways of communication enabling users to make their ideas and opinions known to a potential audience comprising millions of people around the world. This information is called User Generated Content" (Chaves et al., 2012). To Shan et. Al. (2017), Social media is an interactive platform through which users create, share, communicate and discuss ideas and express opinions. According to Terttunen (2017), social media is now part of our daily life as it has made communication with friends, family and organisations easier due to its easy accessibility through the availability of internet connection aided by different devices such as mobile devices- phones, tablets, laptops, desktops, and many others. In a research by Icoz, et al. (2018), tourists will always look for information on social media to help in deciding on the destination to visit, and even after the visit, write about their experience about the destination as well. This is because social media is seen as a real time source of information (Mukherjee and Nagabhushanam, 2016). Social media have changed how organisations and publics relate to one another (Lovejoy et al., 2012). Until recently, on-site travel agents have been the most accessed link between consumers and tourism service providers, when planning for a destination. However, due to changes in the communication and information processes as a result of internet expansion, made tourism service providers and consumers interact online directly, diminishing the role of the traditional onsite travel agencies. (Răzvan and Gabriel, 2012).

In tourism, consumers' behaviour is seen to be influenced by the development of ICTs, and Web 2.0 has changed how consumers design and consume travel related products (Buhalis \& Law 2008). During the planning process for travel, social media plays a vital role as it allows access to the experiences of other travellers as an ultimate information source (Chung \& Buhalis 2008; Yoo et al., 2011). Academic literature also signalled a disagreement on the classification of social medi, according to Fotis et al., (2012). They 
collected different grouping from several research works, and they found that some of them propose just two, five, eight, or more than ten social media types. De (2008) offers ten relevant platforms of social media, encouraging users and travellers to post and share their experiences of travel, comments, opinions to serve as a source of information for other users (Xiang \& Gretzel 2010). With the internet, there are hundreds of platforms through which people can interact and share information with other users, such as blogs, forums, wikis, video and photo sharing to social networks, virtual communities, chat rooms and pod-cast (De 2008).

\section{Research Methodology}

The research adopted a Survey research design as the study is about seeking the opinion of people as regards the usage of Social media and mobile devices in travel booking, and its impact on both destination marketing. Both primary and secondary data were collected for this study. Using Yard's Formula, a sample size of 222 was gotten from an estimated Population of 500 Students in Redeemer's University. To reach the sample size, the Convenience Sampling technique was adopted. To collate the primary data, a questionnaire was designed. The survey was designed in two forms: open-ended and close-ended questions. An open-ended question was asked to give the respondents opportunity to answer the way they wan, thereby enabling them to express themselves in their way. On the other hand, closed-ended questions were asked by providing the respondents with options from where to make their choice about the questions asked. The questionnaires were administered and collected personally by the researcher to be able to get honest and not haphazard answers from the respondents.

Two hundred twenty-two questionnaires were distributed among Redeemer's University Students, Ede Osun State, Nigeria. In testing the hypotheses and to answer the research questions, the Chi-square statistical analysis method was used. This was used in knowing the effects of online travel booking on tourism development in Nigeria. The chi-square was calculated using the following formula;

$$
\begin{aligned}
& \mathrm{X}^{2}=\sum(\mathrm{o}-\mathrm{e})^{2} \\
& \mathrm{e}
\end{aligned}
$$

\section{Results}

A total of 222 copies of questionnaires was distributed, while 200 were retrieved. In answering the research question on how the usage of mobile devices affects the travel bookings in Nigeria, first the respondents were asked on the frequency of internet usage for travel, 90 respondents representing $45 \%$ always makes use of the internet, $60(30 \%)$ Most times, $10(5 \%)$ Sometimes, $30(15 \%)$ Rarely, and $10(5 \%)$ Never. It can be implied that majority- whether always, most times or sometimes- making a total of $150(75 \%)$ of the respondents. With this response, a further enquiry was made to know their usage of mobile devices for their internet activities, especially travel. From the collation of data, 140 respondents representing $70 \%$ Always makes use of mobile devices for travel plans and bookings, 20 (10\%) Most times uses mobile devices, 20 (10\%) Sometimes uses mobile devices for travel, 10 (5\%) Rarely, and $10(5 \%)$ Never. Hence, it 
Abiola-Oke et al., Adv. J Social Sci.; Vol. 6 Issue 1, pp: 10-16, 2020

can be concluded that the majority makes use of their mobile devices for travel plans and booking- i.e. both for sourcing information and booking of travel services.

Also, the data showed that most people do rely on information they get from social media, including travel information. From the result, 100 respondents representing 50\% strongly agree, $40(10 \%)$ agree, $20(10 \%)$ undecided, $10(5 \%)$ disagree, and 30(15\%) strongly disagree that Travel related information provided in social media is more trustworthy than mass media advertising (TV, Radio, and Billboards etc.) and travel agents. Furthermore, a test on the significant relationship between the usage of mobile device and travel booking and the relationship between social media and tourists' behaviour. The tables 1 and 2 below show the analysis and interpretation.

Table 1: Relationship Between the Usage of Mobile Devices and Travel Bookings

\begin{tabular}{|l|l|l|l|l|l|}
\hline & $\begin{array}{l}\text { Observed } \\
(\mathbf{O})\end{array}$ & $\begin{array}{l}\text { Expected } \\
(\mathbf{E})\end{array}$ & $\begin{array}{l}\text { Residual } \\
(\mathbf{O}-\mathbf{E})\end{array}$ & $(\mathbf{O}-\mathbf{E})^{\mathbf{2}}$ & $\mathbf{X}^{\mathbf{2}}=\frac{(\mathbf{O}-\mathbf{E})^{2}}{\mathbf{E}}$ \\
\hline Always & 90 & 40 & 50.0 & 2500 & 62.5 \\
\hline Most Times & 60 & 40 & 20.0 & 400 & 10 \\
\hline Sometimes & 10 & 40 & -30.0 & 900 & 22.5 \\
\hline Rarely & 30 & 40 & -10.0 & 100 & 2.5 \\
\hline Never & 10 & 40 & -30.0 & 900 & 22.5 \\
\hline TOTAL & $\mathbf{2 0 0}$ & & & & $\mathbf{1 2 0}$ \\
\hline
\end{tabular}

Table 1 above is an analysis of the usage of mobile devices and travel bookings. The theoretical value for the degree of freedom of 4 using a 95\% level of significance is 9.488 . Since the theoretical value (9.488) is less than the calculated (chi-square) value, the alternative hypothesis (There is a significant relationship between the usage of the mobile device and travel bookings in Nigeria.) is accepted and the null rejected.

Table 2: Significant Relationship between Social Media and Tourist Behaviour

\begin{tabular}{|l|l|l|l|l|l|}
\hline & $\begin{array}{l}\text { Observed } \\
(\mathbf{O})\end{array}$ & $\begin{array}{l}\text { Expected } \\
(\mathbf{E})\end{array}$ & $\begin{array}{l}\text { Residual } \\
(\mathbf{O}-\mathbf{E})\end{array}$ & $(\mathbf{O}-\mathbf{E})^{\mathbf{2}}$ & $\mathbf{X}^{\mathbf{2}}=\frac{(\mathbf{O}-\mathbf{E})^{\mathbf{2}}}{\mathbf{E}}$ \\
\hline SA & 100 & 40.0 & 60.0 & 3600 & 90 \\
\hline A & 70 & 40.0 & 30.0 & 900 & 22.5 \\
\hline U & 10 & 40.0 & -30.0 & 900 & 22.5 \\
\hline D & 10 & 40.0 & -30.0 & 900 & 22.5 \\
\hline SD & 10 & 40.0 & -30.0 & 900 & 22.5 \\
\hline TOTAL & $\mathbf{2 0 0}$ & & & & $\mathbf{1 8 0}$ \\
\hline
\end{tabular}

$$
\begin{aligned}
& \mathrm{X}^{2}(\text { Chi-Square })=175.7895 \\
& \mathrm{Df}=\text { Degree of Freedom }=(\mathrm{R}-1)(\mathrm{C}-1) \\
& \mathrm{R}=\text { Rows } \\
& \mathrm{C}=\text { Columns } \\
& \mathrm{Df}=\text { Degree of Freedom } \quad=(\mathrm{R}-1)(\mathrm{C}-1) \\
& =(5-1)(2-1) \\
& =(4)(1) \\
& =4
\end{aligned}
$$

Table 2 above is an analysis of the relationship between social media and tourist behaviour. The theoretical value for the degree of freedom of 4 using $95 \%$ (i.e. reading 0.05 against 4 ) level of significance is 9.488 . Since the calculated (chi-square) value is greater than the theoretical value (9.488), the alternative hypothesis (there is a significant relationship between social media and tourist/traveller's behaviour) is accepted, and the null hypothesis rejected. 


\section{Conclusion}

Advancement in technology equally has an impact on the diversification of knowledge. Various literature has equally affirmed the role of information as the tool for liberating and unlocking the wealth of a nation. The influence of information and Communication Technologies (ICTs, which is a product of the combination of information and technology has also touched the field of tourism. This work has demonstrated that tourism is not an isolated economic activity; the sector is composed of several branches. The effects of tourism are not limited to foreign earnings alone but also profits from local resources. It was revealed that almost every tourism product could be sold online without the consumer necessarily visiting the place before making any choice since tourism products are not already manufactured goods. Booking of flights and hotel reservations can be made online through e-mail, telephone calls and other internet services, thereby helping to reduce if not remove the time-wasting processes of the old system entirely. It is, therefore, evident that its adoption is necessary for proper inclusion in these benefits and sustainable development of tourism. Although other aspect or e-commerce (e.g. factors affecting e-commerce adoption in Nigerian banks, factors affecting e-commerce adoption in Nigeria organization etc.) exist in the literature, the effect of online travel bookings (internet, social media and mobile) was not measured, and therefore scholars are challenged to investigate these independent variables. The lack of empirical research in the hospitality industry can be identified as the fundamental explanation for the existing deficiency in knowledge of new technology adoption, and as the principal reason why tourism consistently lags other sectors, especially in developing countries. Hence, this study.

\section{Declaration}

\subsection{Competing Interest}

The authors declared that no conflict of interest exist in this work.

\subsection{Informed Consent}

Informed consent was taken from the respondent.

\section{How to Cite this Article:}

Abiola-Oke, E., \& Aina, C. (2019). Effect of Online Travel Bookings and Social Media on Tourism Destination Marketing in Nigeria. Advanced Journal of Social Science, 6(1), 10-16. doi: 10.21467/ajss.6.1.10-16

\section{References}

Bamodu, OO (2005) 'The Legal Landscape for E-Commerce in Nigeria.' Economic Indicators (Journal of Nigerian Economic Summit Group), $11(1)$.

Berno, Tracy and Bricker, Kelly (2001). Sustainable tourism development: the long road from theory to practice. International Journal of Economic Development. Vol. 3; No. 3; pp. 1-17

Buhalis, D., and Law, R. (2008): Progress in information technology and tourism management: 20 years on andten years after the Internet The state of eTourism research. Tourism Management, Volume 29, Number 4 pp. 609-623.

Chaves, M. S., Gomes, R., Pedron, C. (2012): Decision-making based on Web 2.0 data: the small and medium hotels management, ECIS 2012 Proceedings. Paper 65.

Cheyne, J., Downes, M., Legg, S., 2006, Travel agent vs. internet: what influences travel consumer choices? Journal of Vacation Marketing, 12(1), pp.41-57.

Chulwon Kim, (2004). "E-Tourism: An Innovative Approach for the Small and Medium-Sized Tourism Enterprises (Smtes) In Korea”. C) OECD, 2004

Chung, J. Y., Buhalis, D. (2008): Information needs in online social networks, Information Technology \& Tourism Volume 10, pp. $267-281$.

Compete, Inc. (2006). Embracing Consumer Buzz Creates Measurement Challenges for Marketers.

De, Krishna (2008). Social Media Study: Universal McCann Power To The People - Wave 3 Report.

Farrokh, M. (2009). Impact of E-Commerce on Travel and Tourism: A Historical Analysis. International Journal of Management, Vol. 26, No. 3 .

Forrester Research (2006a). trends 2006: Multichannel retail. Available from: www.forrester.com/Research/Document. Accessed on 1st November, 2016

Forrester Research (2006b). best practices in multichannel retailing. Available from: www.forrester.com/Research/Document. Accessed on 1 st November, 2016

Fotis, J., Buhalis, D., Rossides N. (2012): Social media use and impact during the holiday travel planning process, Information and Communication Technologies in Tourism 2012, pp. 13-24. 
Abiola-Oke et al., Adv. J Social Sci.; Vol. 6 Issue 1, pp: 10-16, 2020

Go, M. F. \& Pine, R. (1995). Globalization strategy in the hotel industry. Illustrated edition, Routledge Publishers, London.

Kaplan, A. M. \& Haenlein, M. (2010). Users of the world, unite! The challenges and opportunities of Social Media. Business Horizons, 53(1): 59-68.

Kim, C. (2004), "E-Tourism: An Innovative Approach for the Small and Medium-Sized Tourism Enterprises (SMTES) in Korea", OECD Publishing

Lovejoy, K. Waters, R. D. \& Saxton, G. D. (2012). Engaging stakeholders through Twitter: How nonprofit organisations are getting more out of 140 characters or less. Public Relations Review, 38(2): 313-318.

Mamaghani, F., 2009. Impact of E-Commerce on Travel and Tourism: An Historical Analysis. International Journal of Management. https://www.questia.com/read/1P3-1889954271/impact-of-e-commerce-on-travel-and-tourism-an-historical

Mukherjee, A. \& Nagabhushanam M. (2016). Role of Social Media in Tourism Marketing, International Journal of Science and Research. 5(6): 2026-2033.

Robert Carey, David Kang, and Michael Zea (2012). The trouble with travel distribution. Retrieved at http://www.mckinsey.com/insights/travel_transportation/the_trouble_with_travel_distribution Accessed on July 10, 2019.

Oguntude and Oyeyipo, (2012). Abandonment factors affecting e-commerce transactions in Nigerian. International Journal of Computer Applications. Vol. 46 No. 23 pp 975-887.

Răzvan Dina, Gabriel Sabou, "Influence of social media in choice of touristic destination”, Cactus Tourism Journal Vol. 3, Issue 2/2012, Pages 24-30.

Schaal, D. (2011). PhoCusWright: US Online Travel Market Share Stalling and Suppliers Rule. Available at: https://www.tnooz.com/article/phocuswright-us-online-travel-market-share-stalling-and-suppliers-rule/ (July 10, 2019).

Shan, S., Ren, J. \& Li, C. 2017. The dynamic evolution of social ties and user-generated content: a case study on a Dobuan group, Enterprise Information Systems, 11 (10): 1462-1480.

Sheldon P. (1993). Destination Information Systems. Annals of Tourism Research, Vol. 20, Pg. 633-649.

Terttunen, A., 2017. The influence of Instagram on consumers' travel planning and destination choice, s.l.: Haaga-Helia University of Applied Sciences.

Tonye, C., 2015. Tonye Cole Lauds Growth of E-Commerce In Nigeria [Interview] (23 March 2015).

Turban Efraim, Jae Lee, David King and H. Michael Chung (2000); Electronic Commerce- A Managerial Perspective. New Jersey: Pearson/Prentice Hall.

Turban, E., King, D., Lee, J., \& Viehland, D. (2004). Electronic Commerce: A Managerial Perspective. New Jersey: Pearson/Prentice Hall.

Xiang, Z. \& Gretzel, U. (2010). Role of social media in online travel information search. Tourism Management, 31(2):179-188.

Xinran, L.Y., Dae-Young, K., \& Morrison, A. M. (2006). The Effect of Prior Destination Experience on Online Information Search Behaviour. Tourism \& Hospitality Research, Vol. 6, No. 2, Page 160-78.

Yoo K.H., Gretzel U., and Zach F. (2011). Travel Opinion Leaders and Seekers. In R. Law, M.Fuchs \& F.Ricci (Eds). Information and communication technologies in tourism 2011 (pp 525-535).

Zwass, V. (2003) Electronic Commerce and Organizational Innovation: Aspects and Opportunities. International Journal of Electronic Commerce, 7; 7-37.

Publish your research article in AIJR journals-

$\checkmark \quad$ Online Submission and Tracking

$\checkmark$ Peer-Reviewed

$\checkmark$ Rapid decision

$\checkmark \quad$ Immediate Publication after acceptance

$\checkmark \quad$ Articles freely available online

Retain full copyright of your article.

Submit your article at journals.aijr.in
Publish your books with AIJR publisher-

$\checkmark$ Publish with ISBN and DOI.

$\checkmark$ Publish Thesis/Dissertation as Monograph.

$\checkmark$ Publish Book Monograph.

$\checkmark$ Publish Edited Volume/ Book.

$\checkmark$ Publish Conference Proceedings

$\checkmark$ Retain full copyright of your books.

Submit your manuscript at books.aijr.org 